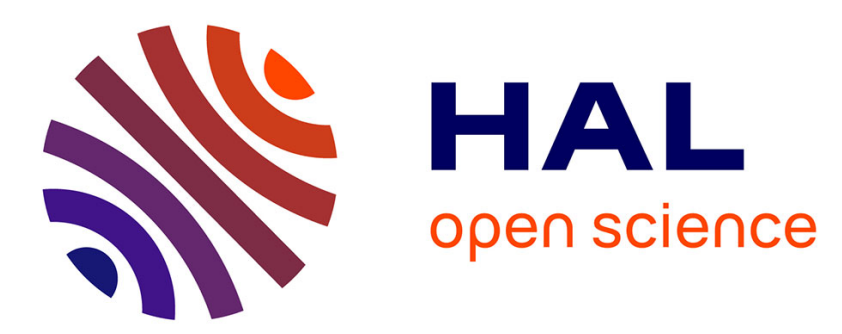

\title{
Can we nudge farmers into saving water? Evidence from a randomised experiment
}

Sylvain Chabe-Ferret, Philippe Le Coent, Arnaud Reynaud, Julie Subervie, Daniel Lepercq

\section{- To cite this version:}

Sylvain Chabe-Ferret, Philippe Le Coent, Arnaud Reynaud, Julie Subervie, Daniel Lepercq. Can we nudge farmers into saving water? Evidence from a randomised experiment. European Review of Agricultural Economics, 2019, 46 (3), pp.393-416. 10.1093/erae/jbz022 . hal-02380993

\section{HAL Id: hal-02380993 https://hal.science/hal-02380993}

Submitted on 5 Dec 2019

HAL is a multi-disciplinary open access archive for the deposit and dissemination of scientific research documents, whether they are published or not. The documents may come from teaching and research institutions in France or abroad, or from public or private research centers.
L'archive ouverte pluridisciplinaire HAL, est destinée au dépôt et à la diffusion de documents scientifiques de niveau recherche, publiés ou non, émanant des établissements d'enseignement et de recherche français ou étrangers, des laboratoires publics ou privés. 


\title{
Can we nudge farmers into saving water? Evidence from a randomised experiment
}

\author{
Sylvain Chabé-Ferret ${ }^{\dagger}$, Philippe Le Coent ${ }^{\star *}$, \\ Arnaud Reynaud $^{\S}$, Julie Subervie ${ }^{* *}$ and Daniel Lepercq ${ }^{\dagger \dagger}$ \\ ${ }^{\dagger}$ Toulouse School of Economics, INRA, University of Toulouse Capitole, \\ Toulouse, France; ${ }^{\ddagger}$ BRGM, Univ. Montpellier, France; ${ }^{\S}$ Toulouse School \\ of Economics, INRA, University of Toulouse Capitole, Toulouse, France; \\ ${ }^{* *}$ CEE-M, Univ. Montpellier, CNRS, INRA, Montpellier SupAgro, \\ France; ${ }^{\dagger \dagger}$ Compagnie d'Aménagement des Coteaux de Gascogne \\ (CACG), France
}

Received April 2018; editorial decision February 2019; final version accepted March 2019

Review coordinated by Sophie Thoyer and Raphaële Preget

\begin{abstract}
We test whether social comparison nudges can promote water-saving behaviour among farmers as a complement to traditional CAP measures. We conducted a randomised controlled trial among 200 farmers equipped with irrigation smart meters in South-West France. Treated farmers received weekly information on individual and group water consumption over four months. Our results rule out medium to large effect-sizes of the nudge. Moreover, they suggest that the nudge was effective at reducing the consumption of those who irrigate the most, although it appears to have reduced the proportion of those who do not consume water at all.
\end{abstract}

Keywords: nudges, behavioural economics, irrigation water use, public policy

JEL classification: D90, Q25, Q58

\section{Introduction}

Agricultural production is among the most water-intensive activities in the European Union (EU). ${ }^{1}$ Water scarcity is already a key challenge in Southern Europe and it is expected to become even more severe and widespread in the coming years because of climate change. From 1960 to 2010, renewable freshwater resources per capita have decreased by 24 per cent in Europe, particularly in southern Europe, and the key objectives of the Seventh

\footnotetext{
*Corresponding author: E-mail: philippe.lecoent@ hotmail.fr

1 The Agriculture, Forestry and Fishing sector represents 51.4 per cent of total water use in the European Union. These figures were provided by the website of the European Environment Agency in 2017.
} 
Environment Action Programme concerning the quantitative management of water between 2002 and 2014 have not been achieved (EEA, 2017). Improving the efficiency of water use, including the efficiency of irrigation in agriculture, is therefore one of the priorities of the CAP 2014-2020. ${ }^{2}$

To fulfil the objectives of the EU Water Framework Directive, which established the principles of a common water policy in Europe in 2000, the European Agricultural Fund for Rural Development (EAFRD) supports two main types of measures at the European level: investment subsidies for waterefficient technologies and agri-environmental schemes where farmers commit to reduce their use of water by substituting leguminous crops for more waterintensive crops in exchange for a predetermined annual payment. ${ }^{3}$ In this article, we consider a new policy instrument called a nudge, which is based on the findings of behavioural sciences and could complement existing CAP measures and contribute to addressing the problem of water resources in Europe. Nudges use subtle modifications of decision contexts to trigger pro-environmental behaviours without altering monetary incentives or the option set itself. A wide variety of nudges have been identified in the literature, including those that leverage individuals' desires to maintain an attractive self-image and those that exploit individuals' inclinations to imitate the behaviour of their peers (Schubert, 2017). This approach is increasingly being adopted in various public policy contexts, like energy conservation or waste reduction. However, it has received little attention with respect to its likely impact on agricultural practices. In this article, we test whether social comparison nudges - reports comparing individual consumption to the consumption of similar neighbours - can increase water-saving behaviour among farmers.

There has been considerable interest recently in the ability of social comparison nudges to trigger changes in pro-environmental behaviours (Croson and Treich, 2014; Schubert, 2017). Indeed, social comparison nudges can be a cost-effective way to change behaviour even if their effects are small because they can be applied to a large population at a small cost. Moreover, social comparison nudges are likely to work because social comparison is one of the most ubiquitous features of human social life. Indeed, individuals often look to others as comparison standards for how to behave, think and feel in order to smoothly coordinate economic exchange, political action and social relationships (Baldwin and Mussweiler, 2018). The effect of social comparison nudges on the adoption of pro-environmental behaviour relies on two different psychological mechanisms. First, a social comparison nudge informs about what other people do, ${ }^{4}$ which can provoke a change in behaviour that is motivated by a fear of receiving a social sanction (Sunstein,

2 Regulation (EU) No 1305/2013 of the European Parliament and of the Council of 17 December 2013 on support for rural development by the European Agricultural Fund for Rural Development (EAFRD) and repealing Council Regulation (EC) No 1698/2005.

3 The conditions of the first measure moreover require that farmers possess proof of the authorisation to withdraw water for irrigation as well as a functioning water meter.

4 This is referred to as the descriptive meaning of the social norm (see Cialdini, Reno and Kallgren (1990) and references therein). 
1996) or by a desire to conform based on the perception that the descriptive norm reflects what is likely to be an effective action to undertake (Thøgersen, 2014). Second, by making the behaviour of others more salient at the moment that a decision is being made, a social comparison nudge can influence behaviour through automatic heuristics (Cialdini, Reno and Kallgren, 1990).

Most of the empirical evidence described in the environmental economic literature on green nudges has focused on consumers' behaviour and has been able to demonstrate significant, albeit small, effects on electricity and water consumption for example (Allcott, 2011; Ferraro, Miranda and Price, 2011; Byerly et al., 2018). It is still unclear though whether social comparison nudges can influence the behaviour of economic agents in a professional or income-generating activity such as farming (Messer, Ferraro and William, 2015; Ferraro, Messer and Wu, 2017). ${ }^{5}$ There are good reasons to believe that the responses to nudges of economic agents in a professional context might differ from responses of consumers. On the one hand, if the activity to be nudged is important for the economic agent's income, they may react intensely to new information about others' practices. This assumption is supported by recent studies that highlight the influence of social norms in farmers' pro-environmental decisions (Burton, 2004; Kuhfuss et al., 2016; Le Coent, Préget and Thoyer, 2018). On the other hand, it is also likely that farmers have already reached a private optimum and are not likely to change their behaviour following a non-monetary incentive. It thus remains an empirical question as to whether social comparison nudges can be efficient in changing strategic agricultural practices, such as the amount of water used for irrigation. This article aims to answer this question. It is, moreover, one of the first studies to present the results of a Randomised Controlled Trial (RCT) in the European farming context (Behaghel, Macours and Subervie, 2019; Dessart, Barreiro-Hurle and van Bavel, 2019). ${ }^{6}$

This study was carried out in partnership with the Compagnie d'Amenagement des Coteaux de Gascogne (CACG), the water distribution company in charge of the management of irrigation infrastructure in the Neste river basin in South West France. In this area, secure access to water irrigation since the 19th century has led to the development of irrigationdependent crops such as maize and more recently soybean. Due to the prevailing weather conditions in this area, the profitability of the production of these crops largely depends on access to water. In recent years, the increased recurrence of droughts and the emergence of environmental constraints have called for the adoption of water-efficient agricultural practices. Strategic changes, such as the adoption of drought-tolerant crops or new irrigation

5 The literature on the adoption of new agricultural technology showed that farmers may learn about the characteristics of a new technology from their neighbours' experiments (Conley and Udry, 2001).

6 As Behaghel, Macours and Subervie (2019) point out, the implementation of an RCT represents a real challenge in the European context, where evaluators are generally confronted with many kinds of technical and political obstacles. 
equipment, are currently promoted by the CAP. Tactical adjustments, such as more precise matching of irrigation activity to crop needs or the avoidance of wasted water, also contribute to conserving the resource.

In the summer of 2017, we implemented an RCT among 200 farmers equipped with smart meters, who were customers of the CACG, to test the effectiveness of a social comparison nudge to reduce their use of water for irrigation. The use of smart water meters and an automated texting platform made it possible to send inexpensive weekly text messages that communicated information to farmers about their own water use as well as that of their neighbours. Our analysis of the data does not show any significant impact of the treatment on average total consumption. However, the treatment seems to have decreased the proportion of farmers who consume more than 80 per cent of their quota, which suggests that social comparison nudges can be effective at influencing the behaviour of those who irrigate the most and who are also presumably more likely to waste water. Our results moreover indicate that the intervention triggered unexpected consumption decisions among those who would have not consumed any water in the absence of intervention, which is referred to as the boomerang effect in the literature.

The article is structured as follows. Section 2 reviews several key findings in the rapidly growing literature on green nudges. Section 3 presents the context of the study. Section 4 describes the experimental design and the data. Section 5 presents the results. We discuss these results in Section 6 and conclude with policy implications in Section 7.

\section{Literature on social comparison nudges}

A large amount of research in economics and psychology has been devoted to testing the effect of social comparison nudges on pro-environmental behaviour using experimental approaches (Farrow, Grolleau and Ibanez, 2017). Social comparison nudges, based on a comparison between individual consumption and collective group consumption, have been shown to have an effect on the reduction of households' electricity and water consumption (Nolan et al., 2008; Allcott, 2011; Ferraro, Miranda and Price, 2011; Ayres, Raseman and Shih, 2013; Costa and Kahn, 2013; Ferraro and Price, 2013). Similar results have been obtained on curbside recycling (Schultz, 1999) and guests' towel reuse in hotels (Goldstein, Cialdini and Griskevicius, 2008). There are, however, contradictory results on whether social comparison nudges have long term effects, with some authors finding that they do (Ferraro, Miranda and Price, 2011; Allcott and Rogers, 2014) and others that they do not (Dolan and Metcalfe, 2015).

Several studies have found evidence of a boomerang effect of social comparison nudges. Informing households of the behaviour of their peers, for example, has been shown to drive some households to increase undesirable behaviours (Cialdini, Kallgren and Reno, 1991). Schultz et al. (2007) find that providing information on average energy usage produced either desirable energy savings or on the contrary an increase of energy consumption, 
depending on whether households were already consuming at a high or a low rate, respectively. This boomerang effect was, however, eliminated when the social information nudge was coupled with an injunctive norm message in the form of an emoticon (a smiling face when consumption was below average), indicating that a below-average level of energy consumption is socially desirable. In a similar way, Ayres, Raseman and Shih (2013) run two RCTs in partnership with utility companies that provide electricity and natural gas and find that treated households that had been in the lowest deciles of energy use prior to the treatment actually increase their energy usage in response to the intervention.

Schubert (2017) provides two explanations for the boomerang effect. First, providing information about the descriptive norm may give agents a socalled 'moral license' to continue engaging in grey behaviour (Cialdini et al., 2006). Second, the phenomenon may result from what social psychologists refer to as 'normalisation', or the idea that individuals tend to move closer to the norm they perceive as currently prevailing among their peers (Sherif, 1935). Some studies moreover suggest that heterogeneity in response to social comparison nudges may also come from individual preferences. Costa and Kahn (2013) show that social comparison nudges are two to four times more effective with political liberals than with conservatives. Goldstein, Cialdini and Griskevicius (2008) highlight that the influence of social comparison nudges depends on the extent to which individuals identify themselves with the reference group. Delmas and Lessem (2014) show that social information has an effect only when it is made public.

Our paper contributes to two streams of literature. The first one investigates the impact of social norms on farmers' decisions to adopt proenvironmental practices (Beedell and Rehman, 1999; Fielding et al., 2005; Defrancesco et al., 2008; Allaire, Cahuzac and Simioni, 2009; Willy and Holm-Müller, 2013; Le Coent, Préget and Thoyer, 2018). These papers reveal the influence of the decision and/or the opinion of others on the adoption of pro-environmental practices or on participation in agri-environmental programmes, but are limited by weak evidence of causality. All of these papers rely on non-experimental approaches and run the risk of confounding the effect of social norms with unobserved and spatially correlated confounders. The second stream of literature uses experimental approaches to manipulate the information that is available to farmers on others' behaviour, in the form of social comparison nudges, and analyse the resulting impact on farmers' decisions. This literature intends both to provide causal evidence of the role of social norms on farmers' pro-environmental decisions and to test the potential of social comparison nudges for their use agri-environmental policies. Kuhfuss et al. (2016) and Chen et al. (2009) analyse the impact of a social comparison nudge on intentions to (i) maintain a pro-environmental practice at the end of an AES and (ii) re-enrol in an AES programme, respectively. Despite their experimental approaches, these papers evaluate the impact of social comparison nudges on intentions rather than actual behaviour, which runs the risk of being affected by hypothetical bias. Other papers 
have also tackled the impact of social comparison nudges on farmer decisions. Peth et al. (2018) conduct an extra-laboratory experiment (Charness, Gneezy and Kuhn, 2013) that tests the impact of a social comparison nudge on the likelihood of complying with the minimum-distance-to-water rule in Germany. These decisions are, however, made in the context of a computerised business management game. Wallander, Ferraro and Higgins (2017) report on the results of a large scale RCT that tests the impact of a social comparison nudge on farmer participation in the Conservation Reserve Programme (CRP), the biggest agri-environmental programme in the United States. Although participation in the CRP is a measure of actual behaviour, it cannot be considered a pro-environmental agricultural practice per se. To our knowledge, our paper is therefore one of the first that reports on the effect of a social comparison nudge on the adoption of pro-environmental practices by farmers.

\section{Context of the experiment}

Our social comparison nudge was implemented in the Neste system located in South-West France. The Neste system is a system of rivers artificially recharged by upstream reservoirs located in the Pyrenées mountains through the $29 \mathrm{~km}$-long Neste canal, which was constructed between 1848 and 1862 to overcome low water levels in the rivers of Gascony. The Neste system covers an area of 800,000 ha and gathers the catchment areas of 17 main rivers. The land in this area is mainly dedicated to agriculture, with about $5,000 \mathrm{~km}^{2}$ cultivated, of which $50,000 \mathrm{ha}$ are irrigated. The experiment is implemented in three watersheds: Arros, Baises and Boues.

The Neste system is managed by a single operator, the CACG. The public service mission of the CACG consists of contributing to the economic development of the Neste area through land use planning and the management of water resources. One important task of the CACG is to allocate water across consumptive uses (domestic consumption, considered as an absolute requirement, and irrigation, which can be limited in the event of a drought) and quality requirements (ecological flows). The relationship between the CACG and the farmers using the CACG water network is defined by a formal contract. This contract specifies a discharge rate and a quota associated to each unit of discharge rate a farmer subscribes for. Annual authorisations of water use, a sort of water right, are attributed in each watershed by the French Single Water Users' Associations (Organisme Unique de Gestion Collective or OUGCs). The authorisations are generally attributed on historical grounds (grandfathering) and are not transferable. The OUGC attributes any extra water extraction rights to, in order of priority: young farmers, new applications by farmers who do not currently possess any water rights and, finally, farmers who wish to increase the level of their existing water rights.

Irrigation metering is mandatory. The water pricing mechanism combines a fixed per unit price with volumetric pricing that is triggered when a 
threshold of consumption is reached. ${ }^{7}$ In addition, for consumption above the allocated quota, the volumetric price is multiplied by a factor of 5-10. In some watersheds, the first stage of volumetric pricing does not exist. For example, in the Arros river, the quota is $1,900 \mathrm{~m}^{3} / \mathrm{ha}$. In 2017 , farmers paid a fixed price of $24 € /$ ha with no volumetric pricing under the quota. ${ }^{8}$ Water consumed above the quota is paid at $0.14 € / \mathrm{m}^{3}$. As a consequence, a farmer who uses 110 per cent of the quota will pay $50.6 € /$ ha on average. The price of water is therefore very low when water use remains below the quota, but can become very expensive once the quota is reached.

Agriculture is highly dependent on irrigation in the area of the experiment. Maize and soybean represent a large majority of the irrigated crops, followed to a lesser extent by sunflower, other cereals, tobacco and some vegetable production. In order to manage their irrigation, farmers have access to weekly technical bulletin that provides them with technical advice, information on weather forecasts, crop water needs and the state of water reserves, but no information on the irrigation practices of other farmers. The recent evolution of rainfall patterns and the expected impacts of climate change increase the pressure on water resources and the risk of defaults in the provision of water to farmers throughout the cropping season. The CACG is therefore trying to identify ways to reduce water use among farmers. Since 2004, the CACG has started to replace its traditional water meters with smart meters named CALYPSO meters.

The CALYPSO device is an ultrasonic meter that sends data in real time to a web-interface. These smart meters have two objectives. First, the CACG collects data on farmers' water use in real time and therefore is better able to manage collective water resources, which occurs through the release of water from dams when farmers require it and the retainment of water when it will not be used. Second, the information generated by smart meters can be used to influence individual behaviour. In this paper, we intend to enhance our knowledge regarding how to achieve this second objective by examining the impact of the strategic use of the data generated by smart meters to send social comparison nudges to farmers.

\section{Experimental design and data}

We ran an experiment in which we sent farmers information generated by smart meters on individual and collective water consumption on a weekly basis. This information was conveyed via an SMS-based communication system managed by the CACG. We carried out two experiments in collaboration with the CACG from July to September 2017 in the three watersheds of the Neste System: Arros, Les Baises and Boues. The protocol of these

7 This threshold is around $80-85$ per cent of the quota and the price ranges from 0.02 to $0.03 € / \mathrm{m}^{3}$.

8 Although the term quota is used by the CACG to define its contractual relationship with farmers, it should be viewed more as a binomial pricing scheme than a quota stricto sensu. Farmers are indeed allowed to go above their quota, but they may face a significant marginal price increase in that case. 
experiments has been registered in the American Economic Association's registry for randomised controlled trials (Le Coent, Chabé-Ferret and Reynaud, 2017).

\subsection{Description of the nudge}

In both experiments, we test whether a social comparison nudge delivered by weekly mobile text messages (11 in total) may have an effect on the amount of water that farmers use for irrigation. In both experiments, farmers in the treatment group received an invitation to optimise their water usage along with an estimate of the average amount of water used by their neighbours. The estimate of average water consumption used in the intervention was computed using smart meter readings from the previous week. The smart meter readings are sent to a centralised database, which enabled us to directly observe farmers' decisions and to compute the weekly average of water consumption at the watershed level. The water consumption database is integrated with an automated SMS platform, which enabled us to craft our messages automatically and to send them directly to farmers' mobile phones.

Experiment 1 was run with a sample of 200 farmers equipped with CALYPSO smart meters. One-hundred and one farmers were randomly assigned to the control group and 99 to the treatment group. The control group received the following normative message: 'Hello $\mathrm{Mr} \mathrm{X}$. Water conservation is important for your watershed. Please continue to optimise your irrigation.' In addition to this normative message, farmers in the treatment group received information about their own water consumption as well as the average level of water consumption at the watershed level: 'As of DD/MM, you have consumed XX percent of your water quota. The irrigating farmers in your watershed have used on average XX percent of their quota'. Moreover, for farmers whose water consumption was below average receive a message of congratulations, inserted in the normative message: 'As of DD/MM, you have consumed XX percent of your water quota. CONGRATULATIONS! The irrigating farmers in your watershed have used on average XX percent of their quota'.

Experiment 2 was run with a sample of 261 farmers equipped with traditional water meters. The treatment (131 farmers) and control groups received the same message as received by farmers in Experiment 1, except that they were not provided any feedback on their own consumption (since such information is not provided by traditional meters).

\subsection{Expected effects of the nudge}

Our experimental design is aimed at testing the hypothesis that the above described social comparison nudges can reduce average water consumption. Such a hypothesis is likely to hold if two mechanisms occur simultaneously: farmers who are informed that their consumption is above average will 
reduce their consumption to conform to the norm, while farmers who are informed that their consumption is below average will not adjust their consumption since they already engage in the desired behaviour. As mentioned in Section 2, reasons for farmers to conform to the norm may be (i) the fear of receiving a social sanction, (ii) the fact that the norm reveals what is likely to be effective behaviour and (iii) automatic heuristics.

In the context of a shared water resource, a social comparison nudge may also exacerbate the risk of over-consumption. Indeed, irrigation systems are a typical common-pool resource (Ostrom, 1992) and it is well known that the 'tragedy of the commons' may occur in highly valued open-access commons (Hardin, 1968). By learning that the average consumption of the watershed is low (at least lower than their own consumption), farmers can deduce that large quantities of water are available and therefore choose to increase their consumption. This strategic effect is the opposite of the intended social norm effect and no prior evidence enables us to anticipate which of the two will prevail.

\subsection{Specific features of the nudge}

Our design has six important features. First, sending messages to the control group enables us to avoid Hawthorne effects, i.e. behavioural changes that result simply from an awareness that one is being observed. In most experiments on electricity consumption the control group did not receive any message, which has led to criticisms that the social information effects detected may only be due to Hawthorne effects (Schwartz et al., 2013).

Second, we measure water consumption as a share of the water quota rather than the volumetric consumption. Water consumption expressed as a share of the quota can be used to compare water consumption for farms of different sizes and producing different crops. Providing consumption information in terms of share of the quota also reduces the cognitive burden as farmers also pay for their water use according to this same indicator of consumption.

Third, the social information on water use is provided at the watershed level (and for the Arros river, also at the province level). We consider that the reference level of water consumption should be associated with a group that shares a similar social identity (Goldstein, Cialdini and Griskevicius, 2008) or a similar production context.

Fourth, we exclude farmers with zero consumption when computing the average consumption (in percentage of the quota) for each geographical group of farmers equipped with CALYPSO smart meters. With this decision, we wanted to avoid confusing farmers by confounding decisions made on the intensive and extensive margins.

Fifth, farmers whose water consumption is below average receive a 'Congratulations' message that aims to neutralise a possible 'boomerang' effect (Schultz et al., 2007). 
Sixth, we do not send the 'congratulations' message to farmers who have not used any water at all, as we assume that this may not be the result of a particular effort but rather characterises farmers that are not using their water rights due to their choices of crops for that year.

\subsection{Sampling and data}

In both experiments, the treatment group was determined using a stratified random sampling method. In Experiment 1, the strata were defined by (i) collective or individual irrigation facility ${ }^{9}$; (ii) river basin; (iii) province; (iv) size of the quota and (v) initial consumption at the beginning of the experiment (null or positive). In Experiment 2, the strata were defined by: (i) collective or individual irrigation facility ${ }^{10}$; (ii) river basin; (iii) size of the quota and (iv) consumption as a share of the quota in 2016.

We were informed just before the start of the experiment that some smart meters did not communicate results properly. In order to control for this problem, farmers with defective smart meters were included in a strata. ${ }^{11}$ In what follows, we report the results only for the 152 farmers who had functioning smart meters during the whole period. For this subset of farmers, we have 11 water consumption observations (including the one collected before the experiment started). In Experiment 2, data collection was lengthier, as CACG staff were required to travel to the farms in order to read the water consumption on the meters. For this experiment we have only one observation: cumulative water consumption as of February 12, from 239 out of the 261 farmers who were initially part of the experiment. This is due to the closure of 22 contracts during the season.

After randomisation, the balance between the treatment and control groups was tested regarding water quota, water consumption in 2016 (in volume), water consumption in 2016 (as a share of quota) and water consumption in 2017 before the start of the experiment (as a share of quota). We moreover crossed the data set with the 2010 Agricultural Census and were able to examine the balance regarding several additional variables, as shown in Table 1.

\section{Results}

We first examine the effect of the social comparison nudges on total water consumption in each experiment. This analysis was pre-registered. We then

9 Collective irrigation facility, or ASA, group several farmers. There were initially four ASAs in Experiment 1. ASAs, although they represent several farmers, are considered as single observations in our sample since we do not have information on the consumption of individual farmers. In the interest of simplicity, we refer to water users as farmers throughout the text. Only ASA leaders received the weekly text messages.

10 There are 19 ASAs in Experiment 2.

11 These farmers received the same information as farmers of Experiment 2 for the beginning of the experiment. Beginning on 22 August 2017, 30 farmers had their smart meters repaired and started receiving complete information. 
Table 1. Main characteristics of farmers by group

\begin{tabular}{|c|c|c|c|c|}
\hline \multirow[b]{2}{*}{ Sample used in Experiment 1} & \multirow[b]{2}{*}{ Nb. obs. } & \multicolumn{2}{|c|}{ Mean values } & \multirow[b]{2}{*}{$t$-stat } \\
\hline & & Treated & Control & \\
\hline 1. Irrigated land (ha) & 152 & 23.4 & 29.3 & 0.09 \\
\hline 2. Water consumption in $2016\left(\mathrm{~m}^{3}\right)$ & 152 & 23,529 & 35,124 & 0.95 \\
\hline 3. Water consumption in 2016 (\% of quota) & 152 & 0.49 & 0.42 & -0.68 \\
\hline 4. Water consumption on 5 July 2017 (\% of quota) & 152 & 0.058 & 0.06 & 0.14 \\
\hline 5. Farmer's age (years) & 111 & 53.05 & 55.16 & -1.07 \\
\hline 6. Farm size (ha) & 111 & 87.67 & 88.90 & -0.11 \\
\hline 7. Total maize sown area (ha) & 111 & 33.90 & 31.08 & 0.41 \\
\hline 8. Irrigated maize area (ha) & 111 & 27.10 & 28.67 & -0.23 \\
\hline 9. Total irrigated area (ha) & 111 & 37.25 & 36.67 & 0.08 \\
\hline 10. Area under property (ha) & 111 & 35.55 & 36.98 & -0.21 \\
\hline 11. Agricultural farming (yes $=1$ ) & 111 & 0.05 & 0.07 & -0.41 \\
\hline 12. Annual work unit (number) & 111 & 2,013 & 1,514 & 1.52 \\
\hline 13. Farmers and co-farmers (number) & 111 & 1.46 & 1.24 & 1.94 \\
\hline 14. Dairy cows (number) & 111 & 9.52 & 10.45 & -0.22 \\
\hline 15. Suckler cows (number) & 111 & 15.63 & 10.96 & 1.00 \\
\hline \multicolumn{5}{|l|}{ Sample used in Experiment 2} \\
\hline 16. Irrigated land (ha) & 239 & 34.2 & 27.1 & -1.01 \\
\hline 17. Water consumption in $2016\left(\mathrm{~m}^{3}\right)$ & 239 & 71,533 & 59,590 & -0.62 \\
\hline 18. Water consumption in 2016 ( $\%$ of quota) & 239 & 0.49 & 0.48 & -0.22 \\
\hline 19. Farmer's age (years) & 166 & 54.09 & 54.11 & -0.01 \\
\hline 20. Farm size (ha) & 166 & 82.10 & 94.19 & -0.26 \\
\hline 21. Total maize sown area (ha) & 166 & 33.23 & 32.62 & 0.11 \\
\hline 22. Irrigated maize area (ha) & 166 & 30.58 & 29.60 & 0.18 \\
\hline 23. Total irrigated area (ha) & 166 & 36.65 & 35.54 & 0.19 \\
\hline 24. Area under tenant farming (ha) & 166 & 55.55 & 66.36 & -1.03 \\
\hline 25. Area under property (ha) & 166 & 26.55 & 27.83 & -0.25 \\
\hline 26. Agricultural farming (yes $=1$ ) & 166 & 0.06 & 0.04 & 0.79 \\
\hline 27. Annual work unit (number) & 166 & 1,674 & 2,015 & -1.46 \\
\hline 28. Farmers and co-farmers (number) & 166 & 1.46 & 1.36 & 0.97 \\
\hline 29. Dairy cows (number) & 166 & 3.90 & 5.45 & -0.59 \\
\hline 30. Suckler cows (number) & 166 & 13.90 & 11.01 & 0.58 \\
\hline
\end{tabular}

Note: Sources of data are CACG (lines 1-4 and 16-18) and French Agricultural Census (lines 5-15 and 19-30). Some CACG farmers were not found in the census (because their identification number was not available or the farm did not exist yet when the census took place), which is why the number of observations is lower for census variables.

examine the heterogeneity of treatment effects. This last part of the analysis was not pre-registered. We present these results nevertheless, since they provide interesting additional insights regarding the effects of a social comparison nudge. 


\subsection{Impact on total and weekly water consumption}

Figure 1 shows the cumulative water consumption over time in Experiment 1. These results suggest that the gap between the two groups widens over time, and that consumption tends to be higher in the control group than in the treated group after 22 August. As shown in Table 2, this difference is, however, not very large and we cannot reject the null hypothesis of no difference between groups at the end of the period. The average consumption in the treated group reaches 26 per cent of the quota on September 12 (Col. 1) compared to 27 per cent in the control group (Col. 2). For Experiment 2, we find

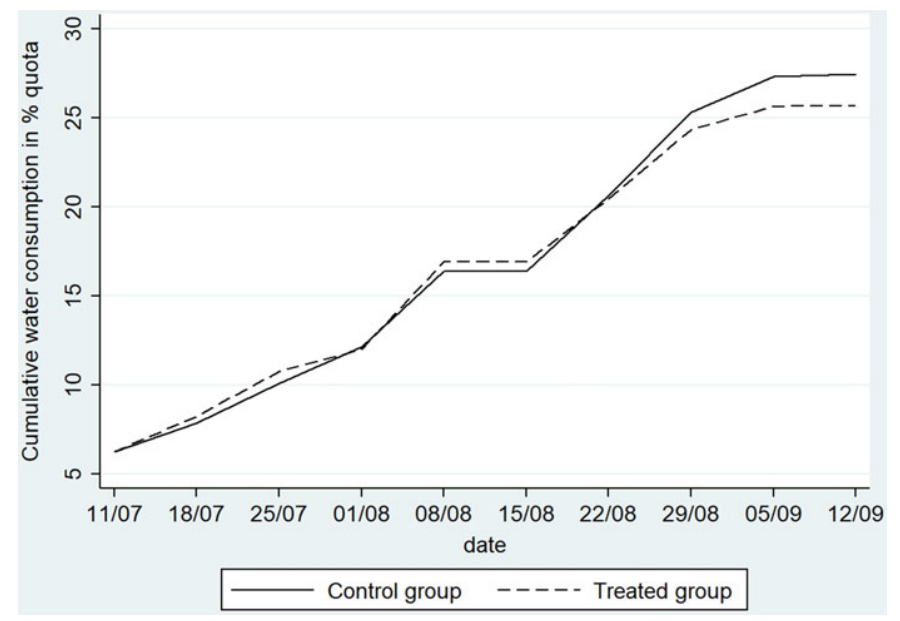

Fig. 1. Cumulative water consumption over time by group (Experiment 1).

Table 2. Impacts of the nudge on water consumption

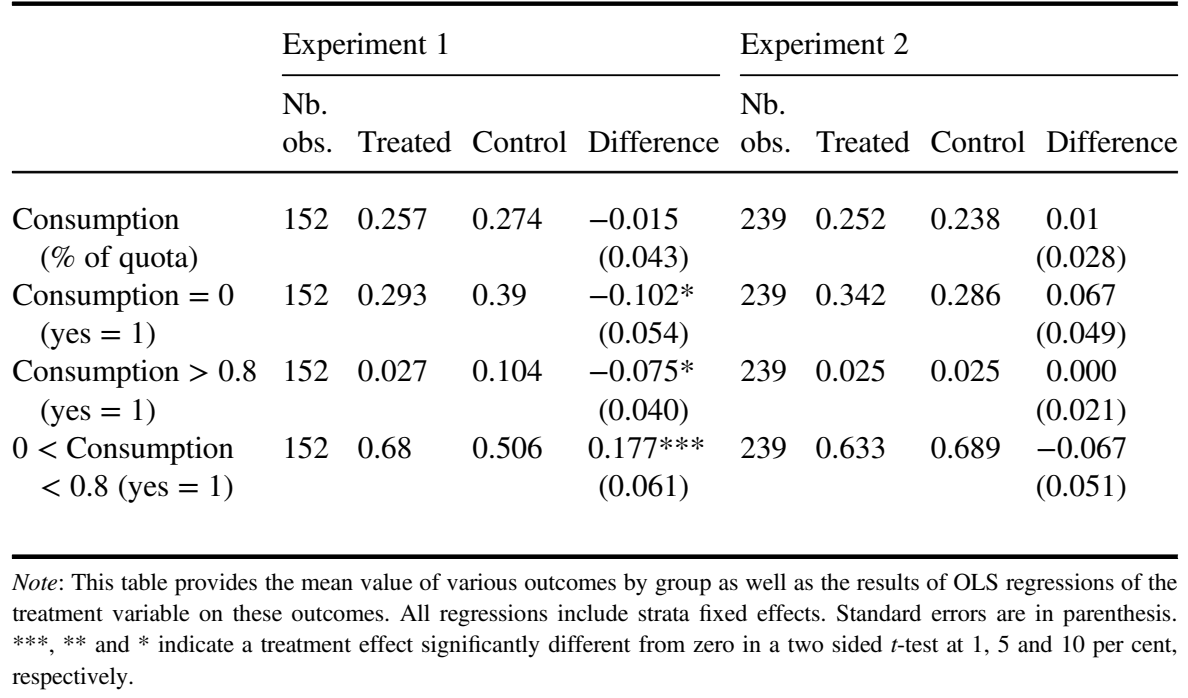




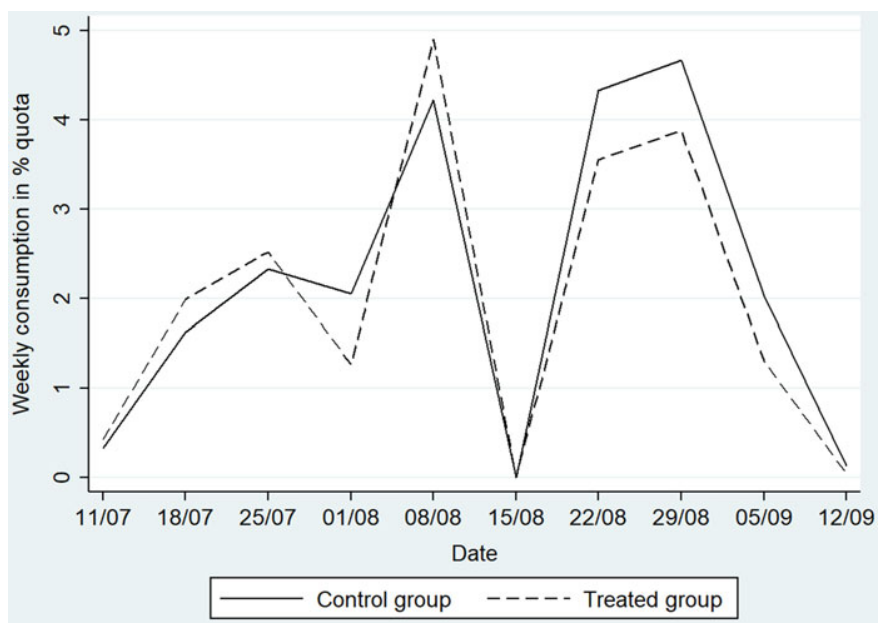

Fig. 2. Weekly water consumption over time by group (Experiment 1).

that 25 per cent of the quota is used in the treated group (Col. 4) and 24 per cent is used in the control group (Col. 5). ${ }^{12}$ Again, the null hypothesis of no impact cannot be rejected.

We then turn to weekly water consumption levels to investigate whether the intervention had an effect during particular periods of the experiment. Figure 2 reveals that the gap between the two groups peaked on 22 and 29 August. Given our level of precision, we are, however, unable to detect significant differences in water consumption at these dates.

\subsection{Heterogeneous effects of the intervention}

We then examine whether the absence of an average treatment effect conceals opposing heterogeneous effects within the sample. Figure 3 shows the distribution of water consumption in both groups in Experiment 1. Three main results emerge. First, the number of farmers consuming no water is higher in the control group. Second, the number of farmers whose consumption exceeds 80 per cent of the quota is smaller in the treatment group. Third (and consequently), the number of farmers consuming some water but less than 80 per cent of their quota is larger in the treatment group. This suggests that the social comparison nudge prompted some farmers who would not have consumed water to start consuming and also changed the behaviour of high consumers, discouraging them from consuming more than 80 per cent their quota.

12 An analysis of the effect of the intervention on volumetric consumption per hectare confirms this absence of effect: we find a negative but insignificant effect of the social comparison nudge of $-79.1 \mathrm{~m}^{3} / \mathrm{ha}( \pm 194.5)$ in Experiment 1 and $10.4 \mathrm{~m}^{3} / \mathrm{ha}( \pm 205.9)$ in Experiment 2. 


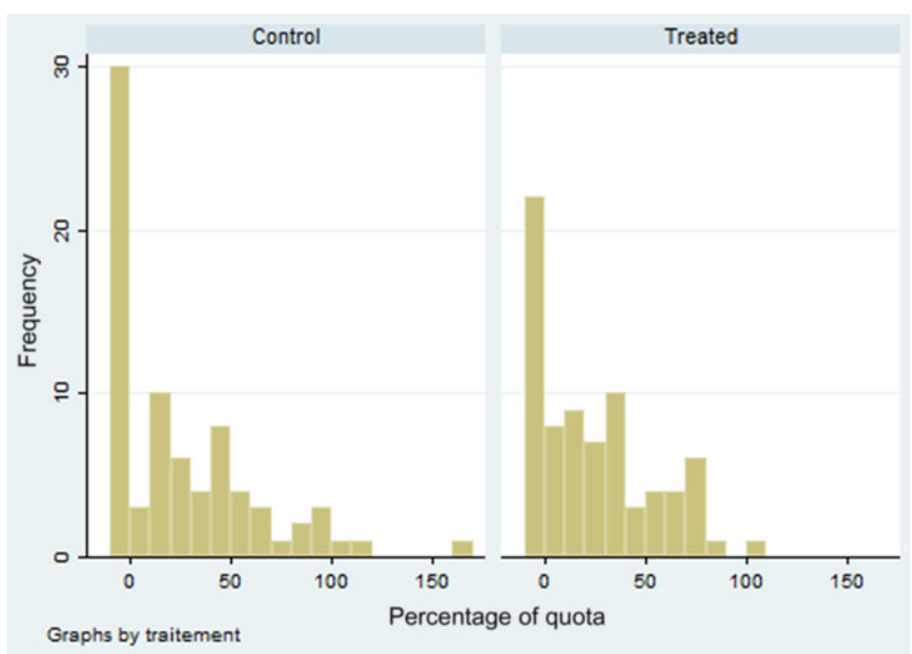

Fig. 3. Distribution of water consumption by group (Experiment 1).

Statistical analysis broadly supports the impression generated by Figure 3. Table 2 shows the results of OLS regressions of the treatment variable on a dummy variable that equals one when a farmer does not consume any water during the season and zero otherwise. The results show that the intervention significantly decreased the proportion of farmers who did not consume water by 10 percentage points, from 39 to 29 per cent on average. ${ }^{13}$ Figure 4 , moreover, shows that this effect appeared gradually over the course of the experimental period. Note that this estimate is statistically significant at the 10 per cent level only - the 95 per cent confidence interval is $10.2 \pm 10.6$ percentage points - and this is only suggestive of possible effects. ${ }^{14}$

Table 2 also provides the results of OLS regressions of the treatment variable on a dummy variable that equals one when a farmer consumed more than 80 per cent of the quota during the season and zero otherwise. The results indicate that the intervention significantly decreased the proportion of farmers who consumed more than 80 per cent of their quota by 7 percentage points, from 10 to 3 per cent. Again, this estimate is statistically significant at the 10 per cent level only and the 95 per cent confidence interval is $7.5 \pm 7.8$ percentage points. Accordingly, the proportion of farmers who consumed more moderately, i.e. between zero and 80 per cent, significantly increased by 17 percentage points - from 51 to 68 percentage points. This result is more precise than the previous ones: $17.7 \pm 12.0$ percentage points, suggesting that the nudge yields to a clustering of water consumption around the mean in Experiment 1.

13 We moreover ran robustness checks in order to take into account meter replacement during Experiment 1. The same results hold. They are displayed in Table A1.

14 We express the precision of our results by reporting the size of the half 95 per cent confidence interval around them. 


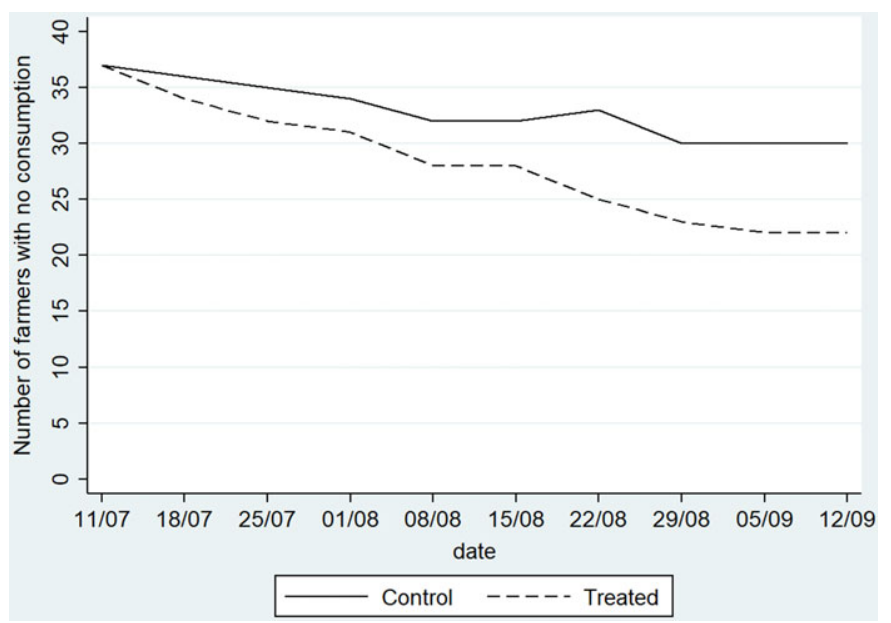

Fig. 4. Number of farmers with no water consumption over time (Experiment 1).

We then ran the same regressions using data from Experiment 2. The results do not reveal any of the effects detected in Experiment 1.

\section{Discussion}

Although the results of this pilot cannot yet be generalised, they call for some comments. We discuss five important features of the study in the following.

\subsection{Two experiments}

The RCT methodology provides a good control for selection bias. In each of the experiments, the control and treatment groups are not systematically different before our intervention for observable and unobservable variables, thanks to the spatially stratified random allocation of the treatment. This is verified with the balancing tests presented in Table 1 . We therefore consider the results of each experiment to be trustworthy. The allocation between Experiment 1 and Experiment 2 was not, however, under our control. Farmers equipped with smart meters are treated in Experiment 1 and those with classic meters are treated in Experiment 2. Being in one experiment or the other therefore depends on how the installation of smart meters was carried out. The CACG did not indicate any systematic bias in the roll out of smart meters. We can therefore compare the results of the two experiments in order to refine the interpretation of our results, but this comparison is limited by a potential selection bias between the two experiments. 


\subsection{Specificity of the context}

The results of each experiment are specific to each of their specific contexts, especially regarding weather conditions. The winter of 2017 was very dry, which led to a limited water reserve in the dams at the beginning of the growing season. Water quotas had already been reduced at the onset of the season in anticipation of a water shortage. Nevertheless, the growing season was marked by regular rainfall that eased the fear of water restrictions and reduced the use of irrigation. There is therefore a need to replicate these experiments in different contexts in order to explore the extent to which our results can be generalised. It is possible, for example, that the reduction in water use among high consumers observed in Experiment 1 would be of a lower magnitude in a dryer year because the marginal cost of complying with the norm (i.e. by reducing irrigation) would be larger. Similar trade-offs between social or cultural norms and economic incentives have already been found with respect to fertility decisions (Chabé-Ferret, 2016).

\subsection{Farmers versus consumers}

Our results suggest that professional farmers do not seem to react much more to social comparison nudges than consumers do. Previous results indeed show that the effect of social comparison nudges on electricity or water consumption by households are very small, in terms of Cohen's $d$ (Baguley, 2009). ${ }^{15}$ We reject large and medium effects of the social comparison nudge in both of our experiments. For water consumption, the Cohen's $d$ corresponding to the extreme of the 95 per cent confidence interval of the impact of the nudge is -0.29 in Experiment 1 and -0.13 in Experiment 2. Our results nevertheless leave open the possibility that farmers respond slightly more than households to social comparison nudges. It remains to be seen whether farmers react in the same way as consumers (with very small responses), more (with small responses) or not at all. Larger, more precise experiments will be needed in order to answer this question.

\subsection{Boomerang effect}

The results of Experiment 1 provide evidence of a boomerang effect of a social comparison nudge among professional economic agents. We believe that some farmers who had not originally planned to use water ended up using some after receiving the nudge. One explanation for this result might be that some farmers who did not plan to use water nonetheless decided to use some on crops that usually do not require much water, such as sunflowers, or that can grow without irrigation (which comes at a cost in terms

15 A large effect is defined as a Cohen's $d$ of the order of 0.8. A medium effect is defined as a Cohen's $d$ of the order of 0.5. A small effect is defined as a Cohen's $d$ above 0.2 and a very small effect as Cohen's $d$ of the order of 0.01 . Cohen's $d$ is computed by dividing the treatment effect by the standard deviation of outcomes in the control group. 
of yields), such as soybeans. Two features of our experiment may have combined to generate a boomerang effect at the extensive margin. First, we did not add the 'congratulations' message for farmers with zero consumption since we were unsure how they would interpret this message. Second, we only computed average water consumption for farmers who consumed a strictly positive amount of water, in order not to confuse farmers about intensive versus extensive margins of water consumption. We tried to make this clear in the message by saying that the average consumption is computed for farmers that do irrigate. But if interpreted incorrectly as an unconditional average, and in combination with the absence of a 'Congratulations' moderator, this may well have given the impression to farmers who were not consuming water that everybody else was consuming water and that we were encouraging them to do so too.

The results from Experiment 2 may help to shed some light on the reasons for the boomerang effect. The results from Experiment 2 do not provide evidence in favour of a boomerang effect. Because Experiment 2 only differs from Experiment 1 insofar as farmers in the former are not sent information on their own consumption, we see at least four possible explanations for the lack of treatment effect in Experiment 2. First, comparing their own consumption with that of their neighbours might have triggered those who previously consumed no water to begin consuming water. This interpretation is a bit contrived since one may assume that farmers who do not consume any water are already aware of this. Although we do not provide any additional information to these farmers in Experiment 1 as compared to Experiment 2, we do increase the salience of the comparison between their own lack of consumption and the positive consumption of others. This difference in salience between experiments may therefore help to explain the boomerang effect observed in Experiment 1.

Second, it is possible that receiving information on their own consumption does not in fact impact farmers consuming no water. If this is the case, the provision of this information in Experiment 1 but not in Experiment 2 cannot be a source of the difference in treatment effects observed, and may instead only be the result of sampling noise (given that the confidence intervals in both experiments overlap) or of differences in the samples between Experiments 1 and 2 .

A third possible interpretation is that farmers who received information that they have not used their quota every week may have felt scrutinised by the CACG for their absence of water consumption, despite owning the rights to do so. They may even have felt the threat of losing their water quota for the following year, which could have led them to use some water in order to avoid this threat.

Fourth, a final possibility is that receiving information regarding their own consumption revealed to farmers in Experiment 1 that they had dysfunctional smart meters. If farmers in the treatment group that had consumed some water received information that their registered consumption was actually zero, they may have called the CACG and requested a new smart meter, 
thereby increasing their registered consumption. Since only the treated farmers in Experiment 1 were able to compare their registered consumption with their actual consumption, this behaviour might have generated a spurious boomerang effect. After further investigation, however, we discard this possibility: we do not find significantly more smart meter replacements in the treated sample of Experiment 1 than in the control sample (16 vs. 13), and the same boomerang effect holds when removing farmers whose smart meters had been replaced from the sample, as shown in Appendix A. More research will be needed in order to estimate this potential boomerang effect with more precision and to investigate whether sending a 'Congratulations' message would make this undesirable effect disappear.

\subsection{Strategic behaviour}

The third takeaway from this work is that the hypothesis that strategic behaviour leads to the tragedy of the commons cannot alone explain the data. Indeed, while the boomerang effect among low water consumers observed in Experiment 1 is compatible with a tragedy of the commons narrative, the decrease in consumption at the top of the distribution is not. On the contrary, a tentative interpretation of this result is that the farmers who consume the most reduced their consumption in order to conform to the prevailing norm. We cannot, however, disentangle whether farmers follow this norm out of fear of receiving a social sanction, because the nudge provided information regarding behaviour that is likely to be effective, or through automatic heuristics. There is also another possible interpretation of the reduction of large consumption: it might be due to treated farmers being more aware of the precise level of their consumption of their quota and stopping their use of water before going above the quota. This is a real possibility, since it is not easy for farmers to keep track of the share of their quota that they have already consumed. More research will be needed in order to explore the robustness of this effect as well.

\section{Conclusion}

Although improving efficiency of water use in agriculture has been a clear objective of the European CAP for a long time, water scarcity remains a critical issue in Europe, especially in the Mediterranean regions. Agriculture must therefore both contribute to the mitigation of this problem and adapt to the expected increase in droughts. This situation provides an opportunity to design and implement new tools to encourage water conservation among farmers. Among these tools, nudges are considered to be a promising policy tool that is able to complement the other tools already used by European public authorities (EESC, 2017). Nudges also constitute a lower-cost intervention than can potentially be applied to all farmers, unlike other CAP instruments, which are generally based on voluntary participation. 
In this paper, we report on an experiment designed to test whether a social comparison nudge can contribute to promote water-saving behaviour in agriculture. Although our results do not reveal a large or even moderate reduction in average water use, they are nevertheless compatible with the small to very small effects that have been found with respect to the household consumer behaviour. We detect indications of reduction in water consumption among the largest water users, but at the same time the intervention appeared to have stimulated water consumption among farmers who did not previously use any water. The absence of a medium to large treatment effect, as well as indications of an undesirable boomerang effect, calls for (i) larger-scale experiments to be conducted in order to be able to detect effects of a smaller magnitude and (ii) a careful testing of nudges before scaling up their use. More research is therefore needed to strengthen our conclusions on the interest of nudges and avoid potential undesirable effects.

The first direction for further research is to improve the precision of the measured impact of social comparison nudges on water consumption. We are clearly in need of experiments with greater power, with sample sizes in the order of thousands of farmers, in order to be able to detect potentially small effects. One possibility would be to run a large experiment, or to combine several similar experiments, across several EU countries that suffer from water scarcity and where farmers are equipped with smart meters.

The second direction for further research is to improve the targeting of nudges in order to avoid the boomerang effect. Simple strategies such as not sending messages to individuals who use below-average levels of water are possible. More complex strategies might involve the use of Machine Learning methods to determine which farmers react the most to a nudge.

A third direction for further research is to try to improve the effectiveness of the message itself. One way to do this would be to tailor the reference group used to compute average consumption to make it closer to the profile of each farmer. The effectiveness of social comparison nudges depends on whether farmers identify themselves with the reference group used in the nudge (Goldstein, Cialdini and Griskevicius, 2008). In our experiment, we endeavoured to use a 'valid' reference group by communicating the average consumption of farmers in the same department and watershed, i.e. "neighbour' farmers. The use of the consumption in terms of percentage of quota was also chosen in order to ensure comparable values among farmers with different size farms. Ideally, providing more tailored reference groups for farmers of the same type (for example, maize growers/soya growers) would likely be more effective. However, water consumption by farmer type is currently not available. Another approach would be to express social comparisons in monetary terms instead of the percentage of the quota that has been used. $^{16}$

A fourth direction for further research would be to try to find ways to test for strategic interactions with respect to water consumption. One interesting 
possibility offered by smart meters and SMS technologies is the ability to monitor each other's consumption so that enforcing a cooperative equilibrium might become easier if punitive actions such as public sanctions can be used.

A fifth direction for further research is to test how nudges interact with other types of information, such as information on alternative irrigation techniques or weather forecasts, or with other policies, such as peak pricing. Some recent work indeed suggests that there are conditions under which nudges and taxes should coexist (Farhi and Gabaix, 2017). As a case in point, it might be optimal for the CACG to implement a positive price for the first units of water consumption in order to decrease the magnitude of the boomerang effect.

If more evidence confirms that social comparison nudges can curb farmers' water consumption, an important question nevertheless remains: how could this type of nudge be concretely implemented and how it could be incorporated in the CAP? A first task would be to determine which institution would be responsible for implementing such nudges. Authorities in charge of water management at the local scale could be the appropriate institutional setting. In France, OUGCs could be the appropriate structures. These water user associations are indeed in charge of managing and distributing water quotas among farmers over a given territory. Their relatively small size and the fact that all farmers belong to the same territory could make social comparison nudges effective tools for agricultural water management at this scale. Similar institutions also exist in other European countries (i.e. Water User Associations in Spain, Greece and Italy). The reform of the CAP could then include actions targeted at promoting the use of nudges in agricultural water user associations. Since implementing nudges requires some technical expertise that may not be available in agricultural water user associations, some financial aid for a nudge training programme could be considered for the post-2020 CAP.

A second prerequisite for using this type of nudge is the metering of agricultural water use. The social comparison nudge we developed and assessed in our experimental setting should then be viewed as a complement to water metering. Water metering is already a policy tool included in the CAP. More precisely, the new Rural Development Regulation for the 2014-2020 programming period contains particular safeguards with respect to support for investments in irrigation, specifically, linking it to water metering. In addition, the EU (2011) explicitly mentions smart metering in the portfolio of water efficiency measures to be included in the road map to a resource efficient Europe. Some mechanisms to subsidy investments in smart water meters could then be included in the new CAP 2021-2028. This is in line with the 1 June 2018 legislative proposals on the common agricultural policy (CAP) beyond 2020 presented by the European Commission. This proposal stresses the fact that the reform of the CAP should encourage increased investment in innovation, which is essential for a smart, resilient and sustainable agricultural sector. Smart water meters could be part of these innovative investments. 


\section{Acknowledgements}

The authors are grateful to the audiences at a number of seminars in the Center for Environmental Economics of Montpellier, Toulouse School of Economics, and the 6th World Congress of Environmental and Resource Economists. This work is a part of the C4EAU project ('Compteurs d'eau Communicants et Changement de Comportement des irrigants pour une gestion durable des ressources en EAU' R\&S 2017 C4EAU DF-000008) funded by the region Occitanie within the programme Recherche et Société(e)s 2017. More information on this project in available at https://c4eau.wordpress. com/. This work has also received financial support from the French National Research Agency (ANR) through the PENSEE ('Payments for ENvironmental Services: an Evidence-based Evaluation') and the AMEP ('Advancing Methods for Evaluating Environmental/health Policy and wealth') projects.

\section{References}

Allaire, G., Cahuzac, E. and Simioni, M. (2009). Contractualisation et diffusion spatiale des mesures agro-environnementales herbagères. Revue d'Etudes en Agriculture et Environnement 90: 23-50.

Allcott, H. (2011). Social norms and energy conservation. Journal of Public Economics 95: 1082-1095.

Allcott, H. and Rogers, T. (2014). The short-run and long-run effects of behavioral interventions: experimental evidence from energy conservation. American Economic Journal 104: 3003-3037.

Ayres, I., Raseman, S. and Shih, A. (2013). Evidence from two large field experiments that peer comparison feedback can reduce residential energy usage. The Journal of Law, Economics, and Organization 29: 992-1022.

Baguley, T. (2009). Standardized or simple effect size: what should be reported?'. British Journal of Psychology 100: 603-617.

Baldwin, M. and Mussweiler, T. (2018). The culture of social comparison. Proceedings of the National Academy of Sciences of the United States of America 115: E9067-E9074.

Beedell, J. and Rehman, T. (1999). Explaining farmers' conservation behaviour: why do farmers behave the way they do?'. Journal of Environmental Management 57: 165-176.

Behaghel, L., Macours, K. and Subervie, J. (2019). How can randomized controlled trials help improve the design of the common agricultural policy? European Review of Agricultural Economics this issue.

Burton, R. J. (2004). Seeing through the 'good farmer's' eyes: towards developing an understanding of the social symbolic value of 'productivist' behaviour. Sociologia Ruralis 44: 195-215.

Byerly, H., Balmford, A., Ferraro, P. J., Wagner, C. H., Palchak, E., Polasky, S., Ricketts, T. H., Schwartz, A. J. and Fisher, B. (2018). Nudging pro-environmental behavior: evidence and opportunities. Frontiers in Ecology and the Environment, 16(3): 159168.

Chabé-Ferret, B. (2016). Adherence to cultural norms and economic incentives: evidence from fertility timing decisions. IZA Working Paper No. 10269, IZA. 
Charness, G., Gneezy, U. and Kuhn, M. A. (2013). Experimental methods: extralaboratory experiments-extending the reach of experimental economics. Journal of Economic Behavior \& Organization 91: 93-100.

Chen, X., Lupi, F., He, G. and Liu, J. (2009). Linking social norms to efficient conservation investment in payments for ecosystem services. Proceedings of the National Academy of Sciences of the United States of America 106: 11812-11817.

Cialdini, R. B., Demaine, L. J., Sagarin, B. J., Barrett, D. W., Rhoads, K. and Winter, P. L. (2006). Managing social norms for persuasive impact. Social Influence 1: 3-15.

Cialdini, R. B., Kallgren, C. A. and Reno, R. R. (1991). A focus theory of normative conduct: a theoretical refinement and reevaluation of the role of norms in human behavior. Advances in Experimental Social Psychology, 24: 201-234.

Cialdini, R. B., Reno, R. R. and Kallgren, C. A. (1990). A focus theory of normative conduct: recycling the concept of norms to reduce littering in public places. Journal of Personality and Social Psychology 58: 1015-1026.

Conley, T. and Udry, C. (2001). Social learning through networks: the adoption of new agricultural technologies in Ghana. American Journal of Agricultural Economics 83: 668-673.

Costa, D. L. and Kahn, M. E. (2013). Energy conservation 'nudges' and environmentalist ideology: evidence from a randomized residential electricity field experiment. Journal of the European Economic Association 11: 680-702.

Croson, R. and Treich, N. (2014). Behavioral environmental economics: promises and challenges. Environmental and Resource Economics 58: 335-351.

Defrancesco, E., Gatto, P., Runge, F. and Trestini, S. (2008). Factors affecting farmers' participation in agri-environmental measures: a northern Italian perspective. Journal of Agricultural Economics 59: 114-131.

Delmas, M. and Lessem, N. (2014). Saving power to conserve your reputation? The effectiveness of private versus public information. Journal of Environmental Economics and Management 67(3): 353-370.

Dessart, F., Barreiro-Hurle, J. and van Bavel, R. (2019). Behavioural factors affecting the adoption of sustainable farming practices: a policy-oriented review. European Review of Agricultural Economics, this issue.

Dolan, P. and Metcalfe, R. (2015). Neighbors, Knowledge, and Nuggets: Two Natural Field Experiments on the Role of Incentives on Energy Conservation. Becker Friedman Institute for Research in Economics Working Paper No. 2589269.

EEA (2017). Indicator Assessment-Data and maps: use of freshwater resources. Copenhagen, Denmark: European Environment Agency.

EESC (2017). Opinion of the European Economic and Social Committee on 'Towards applying Nudge Thinking to EU Policies'. Official Journal of the European Union, pp. 28-32.

EU (2011). Roadmap to a Resource Efficient Europe. European Commission, COM/2011/ 0571 final.

Farhi, E. and Gabaix, X. (2017). Optimal taxation with behavioral agents. National Bureau of Economic Research Working Paper No. 21524.

Farrow, K., Grolleau, G. and Ibanez, L. (2017). Social norms and pro-environmental behavior: a review of the evidence. Ecological Economics 140: 1-13.

Ferraro, P., Messer, K. D. and Wu, S. (2017). Applying behavioral insights to improve water security. Choices 32 (4): 1-6

Ferraro, P. J., Miranda, J. J. and Price, M. K. (2011). The persistence of treatment effects with norm-based policy instruments: evidence from a randomized environmental policy experiment. The American Economic Review 101: 318-322. 
Ferraro, P. J. and Price, M. K. (2013). Using nonpecuniary strategies to influence behavior: evidence from a large-scale field experiment. The Review of Economics and Statistics 95: 64-73.

Fielding, K. S., Terry, D. J., Masser, B. M., Bordia, P. and Hogg, M. A. (2005). Explaining landholders' decisions about riparian zone management: the role of behavioural, normative, and control beliefs. Journal of Environmental Management 77: $12-21$.

Goldstein, N. J., Cialdini, R. B. and Griskevicius, V. (2008). A room with a viewpoint: using social norms to motivate environmental conservation in hotels. Journal of Consumer Research 35: 472-482.

Hardin, G. (1968). The tragedy of the commons. Science (New York, N.Y.) 162: 1243-1248.

Kuhfuss, L., Préget, R., Thoyer, S., Hanley, N., Coent, P. L. and Désolé, M. (2016). Nudges, social norms, and permanence in agri-environmental schemes. Land Economics 92: 641-655.

Le Coent, P., Chabé-Ferret, S. and Reynaud, A. (2017). Effect of social information on farmers' irrigation decisions. AEA RCT Registry.

Le Coent, P., Préget, R. and Thoyer, S. (2018). Do farmers follow the herd? The influence of social norms in the participation to agri-environmental schemes. CEEM Working Paper 2018-02.

Messer, K. D., Ferraro, P. D. and William, A. (2015). Behavioral nudges in competitive environments: a field experiment examining defaults and social comparisons in a conservation contract auction. Paper presented at the Agricultural \& Applied Economics Association (AAEA) Annual Meeting, San Franciso, CA, 26-28 July.

Nolan, J. M., Schultz, P. W., Cialdini, R. B., Goldstein, N. J. and Griskevicius, V. (2008). Normative social influence is underdetected. Personality and Social Psychology Bulletin 34: 913-923.

Ostrom, E. (1992). Crafting Institutions for Self-governing Irrigation Systems. A publication of the International Center for Self-governance, ICS Press, San Francisco, 111 p.

Peth, D., Musshoff, O., Funke, K. and Hirschauer, N. (2018). Nudging farmers to comply with water protection rules: experimental evidence from Germany. Ecological Economics 152: 310-321.

Schubert, C. (2017). Green nudges: do they work? Are they ethical? Ecological Economics 132: 329-342.

Schultz, P. W. (1999). Changing behavior with normative feedback interventions: a field experiment on curbside recycling. Basic and Applied Social Psychology 21: 25-36.

Schultz, P. W., Nolan, J. M., Cialdini, R. B., Goldstein, N. J. and Griskevicius, V. (2007). The constructive, destructive, and reconstructive power of social norms. Psychological Science 18: 429.

Schwartz, D., Fischhoff, B., Krishnamurti, T. and Sowell, F. (2013). The Hawthorne effect and energy awareness. Proceedings of the National Academy of Sciences of the United States of America 110: 15242-15246.

Sherif, M. (1935). A Study of Some Social Factors in Perception. Archives of Psychology. New York City: Columbia University, 187. 60p.

Sunstein, C. R. (1996). Social norms and social roles. Columbia Law Review 96: 903.

Thøgersen, J. (2014). The mediated influences of perceived norms on pro-environmental behavior. Revue D Economie Politique 124: 179-193.

Wallander, S., Ferraro, P. and Higgins, N. (2017). Addressing participant inattention in federal programs: a field experiment with the conservation reserve program. American Journal of Agricultural Economics 99: 914-931. 
Willy, D. K. and Holm-Müller, K. (2013). Social influence and collective action effects on farm level soil conservation effort in rural Kenya. Ecological Economics 90: 94-103.

\section{A. Appendix}

\section{A.1. Robustness checks}

In order to take into account meter replacement during Experiment 1, we use different strategies. In model (1) we exclude from the data-set farmers who had their meters changed less than 2 weeks before the end of the experiment. In model (2), we exclude all farmers who had their meters changed between 1 July 2017 and 1 December 2017. We indeed consider that meters replaced after the end of experiment may have biased the results during the experiment. We, however, consider that replacement that occurred after 1 December 2017 are due to problems that happened after the experiment and therefore did not affect our results. In model (3), the most restrictive, we exclude all farmers with meters changed between 1 July 2017 and 15 March 2018.

Table A1. Impact of nudges on probability to use no water in Experiment 1 with different models taking into account meter replacement

\begin{tabular}{llll}
\hline & $(1)$ & $(2)$ & $(3)$ \\
\hline Nudge & $-0.115^{* *}$ & $-0.091^{*}$ & $-0.139^{* *}$ \\
& $(0.053)$ & $(0.053)$ & $(0.058)$ \\
Cons. & $1^{* * *}$ & $1 * * *$ & $1 * * *$ \\
& $(0.325)$ & $(0.330)$ & $(0.314)$ \\
$F$ & 12.10 & 14.33 & 11.95 \\
$N$ & 148 & 137 & 123 \\
\hline
\end{tabular}

Note: These OLS regressions include strata fixed effects. 